The 1st International Electronic Conference on Forests

Forests for a Better Future: Sustainability, Innovation, Interdisciplinarity

15-30 November 2020

\title{
Transport work for the supply of pine sawlogs to the sawmill
}

Grzegorz Trzciński, Łukasz Tymendorf

Warsaw University of Life Sciences - SGGW 


\section{Introduction}

Timber transport is a key issue in the wood supply chain, forest management operations, which has a large share in the total cost of harvesting [Hirsch 2011; Shaffer, Stuart 2005], but also has a significant potential for optimization [Greulich 2002; McDonald, Haridass, Valenzuela 2010].

In the analyzes of improving the efficiency of roundwood transport by shortening the operation time (eg waiting for loading / unloading) and delivery distances, the need for cooperation between forestry enterprises, the timber industry and transport companies is emphasized [Frisk et.all 2010; Hirsch, Gronalt 2013; Tymendorf, Trzciński 2020].

In a situation where groups of buyers are not able to organize collective procurement that minimizes costs, the active role is assigned to sellers, which in Poland is reflected in the procedures of selling wood by the State Forests National Forest Holding. 


\section{Purpose and scope}

The aim of the presented research was to analyze the transport work performed during the delivery of large-size pine timber to the sawmill and to determine the factors influencing its size and structure.

The scope was to analyses of transports depending on the:

- period of their realization,

- State Forest District which sells the round wood,

- location of the pine sawlogs,

- journeys with cargo on public and forest roads,

- weight of the load round wood. 


\section{Material and Methods}

The transport work in tonne-kilometers was defined as the multiplication of the kilometers traveled on forest and public roads with the cargo and the weight of the load for each route and the total value for all analyzed transports.

Relevant analyzes were carried out for the supply of pine sawlogs in the period from April 1, 2016 to March 29, 2017, to a sawmill in northern Poland. The transport was carried out by external companies acting on behalf of the sawmill.

The data on kilometers driven on forest and public roads with round wood was determined from data obtained while receiving the load from the driver. Having accurate location data (from the delivery note) it was possible to verify (control) to eliminate incorrect information provided by the driver. 


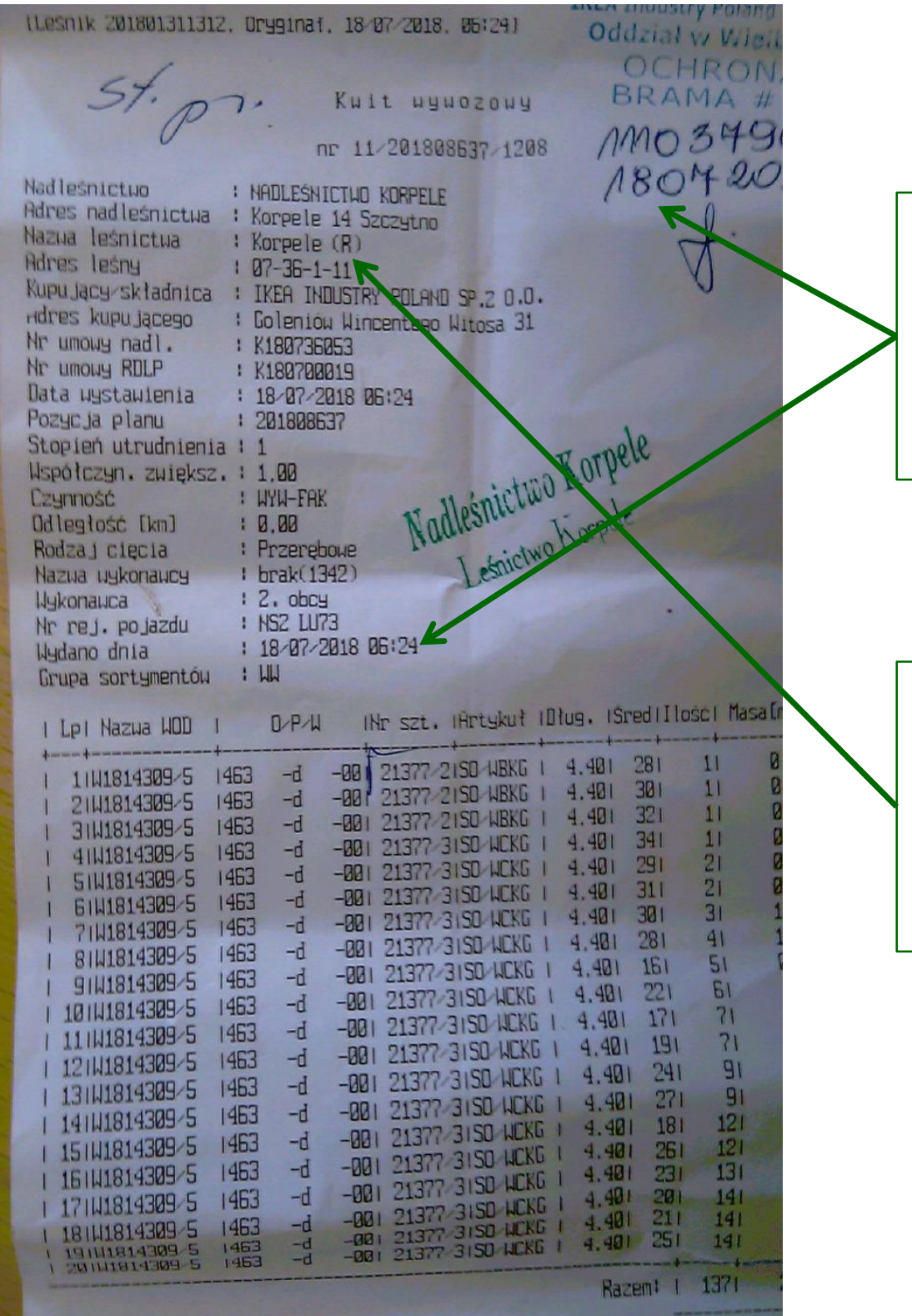

The delivery date resulted from the recipient's documents (sawmill) and the delivery note issued by the State Forest, which allowed for the analysis for individual months.
The place of harvesting the wood is specified on the delivery note by the State Forest, by providing the unique forest address from the information system of the State Forests (SILP). 


\section{Material and Methods}

The weight of the load was determined on the basis of weighing a truck with wood and after unloading (tare) on the wood yard in the plant.
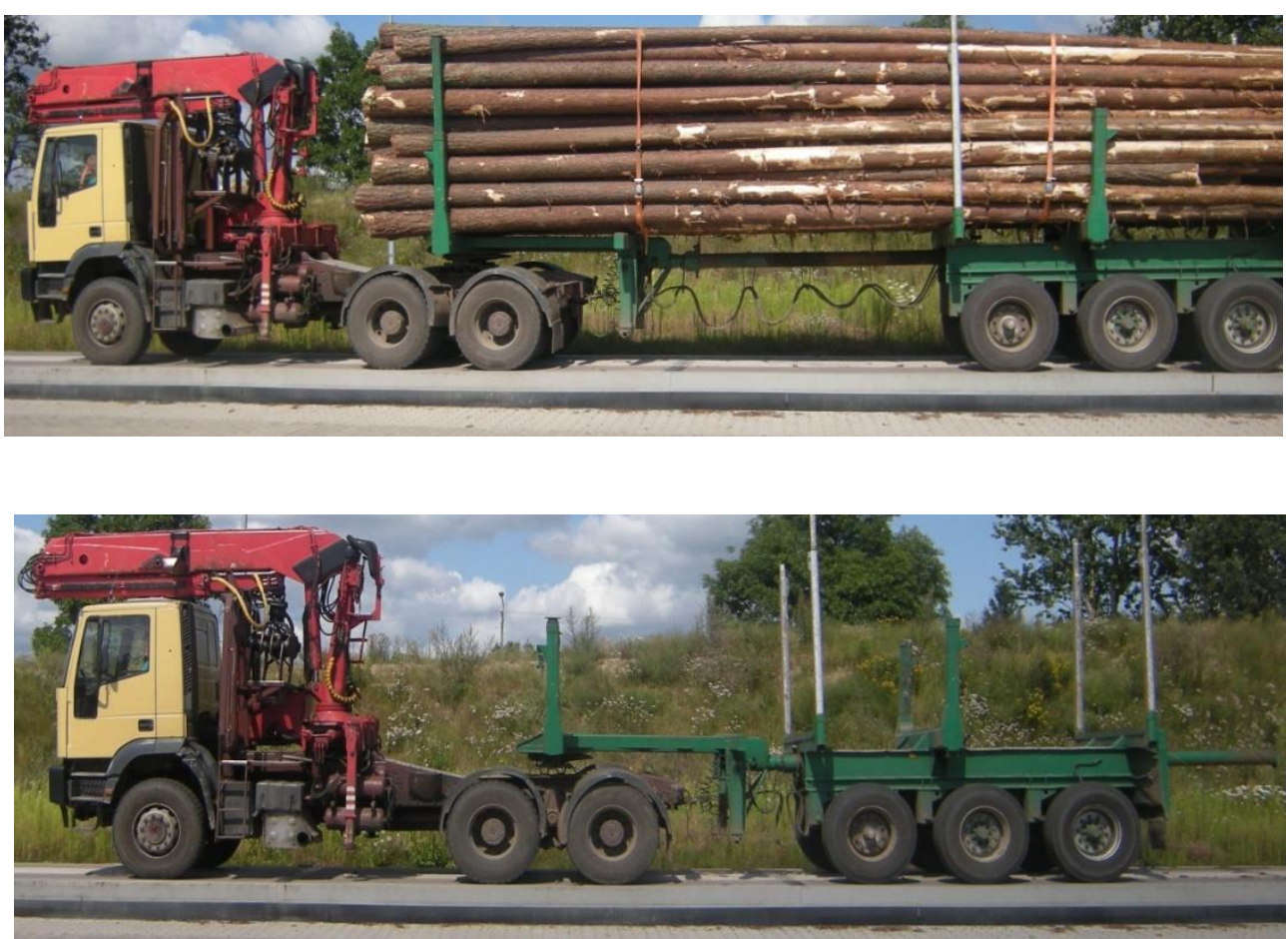

On the handling area, using gravity measurements, we made weight controls of every truck going in GVW, and every truck going out empty set weight. The difference between full and empty vehicle gave weight of load (payload). 


\section{Results}

Characteristic of the State Forest Districts

The analysis covered $1,509(13.97 \%)$ of randomly selected timber transports carried out over a period of twelve months from 40 forest districts, where a load per truck was obtained from one place, single stand. In the analyzed 1,509 transports, 44,336 m3 of round wood was delivered to the sawmill.

Most of the analyzed 129 sawlogs transports to the sawmill were carried out from the Korpele Forest District at an average distance of $34.3 \mathrm{~km}$ with a journeys with a load from 25 to $57 \mathrm{~km}$. In the analyzed deliveries, 30.1\% (454 courses) were carried out from the forest districts: Wielbark, Nidzica, Szczytno, Jedwabno, Korpele, Przasnysz, and Parciaki, from a distance of up to $50 \mathrm{~km}$ (average transport distance). 

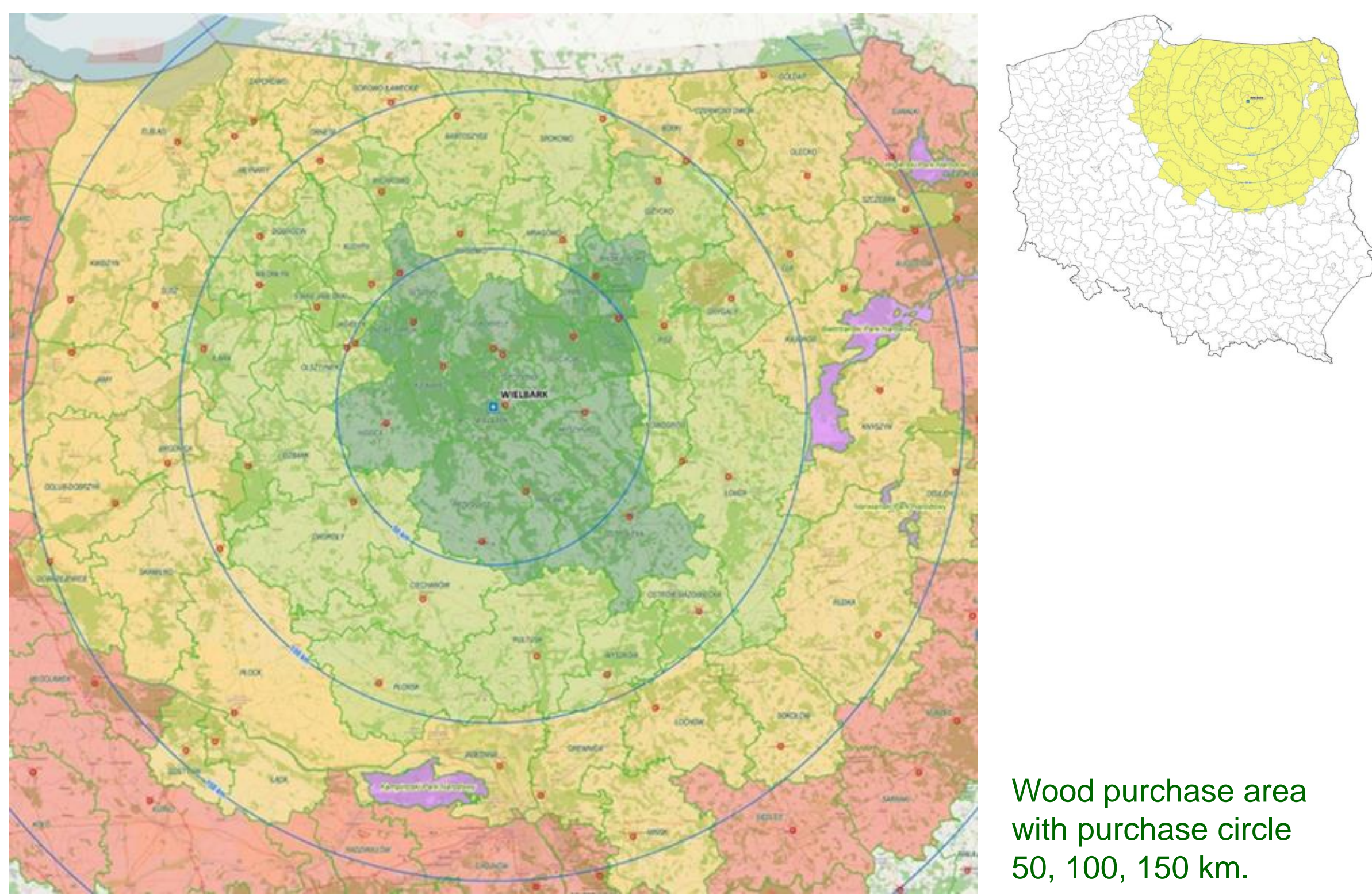

Wood purchase area with purchase circle $50,100,150 \mathrm{~km}$.

Warsaw University of Life Sciences - SGGW, Institute of Forest Sciences, Department of Forest Utilization 159 Nowoursynowska St., 02-776 Warsaw, Poland 


\section{Results}

Characteristics of journeys with a load of timber and the weight of the load

The realization of the analyzed deliveries to the sawmill was associated with the total load journeys (on public and forest roads) at the level of $113,728 \mathrm{~km}$. The average distance of journeys with cargo was $75.4 \mathrm{~km}$ and was characterized by high variability $\mathrm{SD}=39.1$ in the range from $3.0 \mathrm{~km}$ to $274.5 \mathrm{~km}$.

Table. Characteristics of analyzed parameters in wood transportation to sawmill

\begin{tabular}{cccccccc}
\hline Measure & Mean & SD & Min & Max & Q1 & Mediana & Q3 \\
\hline Mass of load (t) & 30.32 & 2.20 & 21.75 & 38.91 & 28.80 & 30.20 & 31.75 \\
$\begin{array}{c}\text { Total driving with } \\
\text { load (km) } \\
\begin{array}{c}\text { Transport work } \\
(\mathrm{tkm})\end{array}\end{array}$ & 75.4 & 39.1 & 3.0 & 274.5 & 45.2 & 74.0 & 98.0 \\
\hline
\end{tabular}

Notes: SD. standard deviation; Q1. first quartile; Q3 third quartile. 


\section{Results}

Characteristics of journeys with a load of timber and the weight of the load

The greatest number of deliveries (on a public and a forest road) was recorded in the range of $70 \div 80 \mathrm{~km}-186$ and $80 \div 90 \mathrm{~km}-182$ transports. In 24 cases, timber was transported over a distance of more than $200 \mathrm{~km}$. Most deliveries were made within 100 $\mathrm{km}$ from the plant, $75.35 \%$ of transports within this radius.

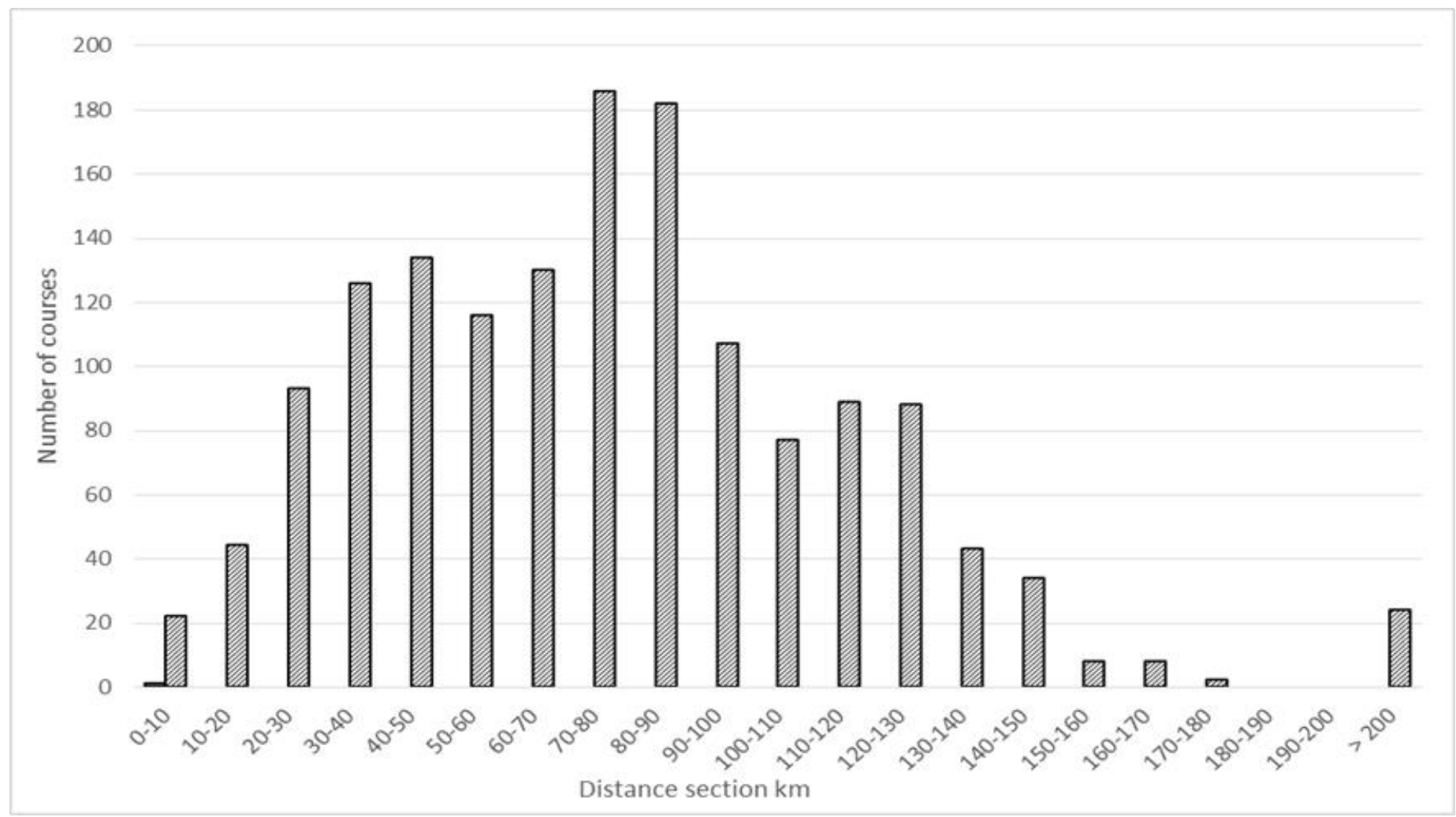

Warsaw University of Life Sciences - SGGW, Institute of Forest Sciences, Department of Forest Utilization 159 Nowoursynowska St., 02-776 Warsaw, Poland 


\section{Results}

Characteristics of journeys with a load of timber and the weight of the load

The average load weight in individual courses is $30.32 \mathrm{t}$ and is very similar between forest districts $(S D=2.20$ and median 30.20), although the Kruskal-Wallis test showed statistically significant differences. Detailed analysis using the multiple mean rank comparison test (Dunn's test) showed that the masses of individual wood loads in transports from 18 forest districts did not differ from each other.

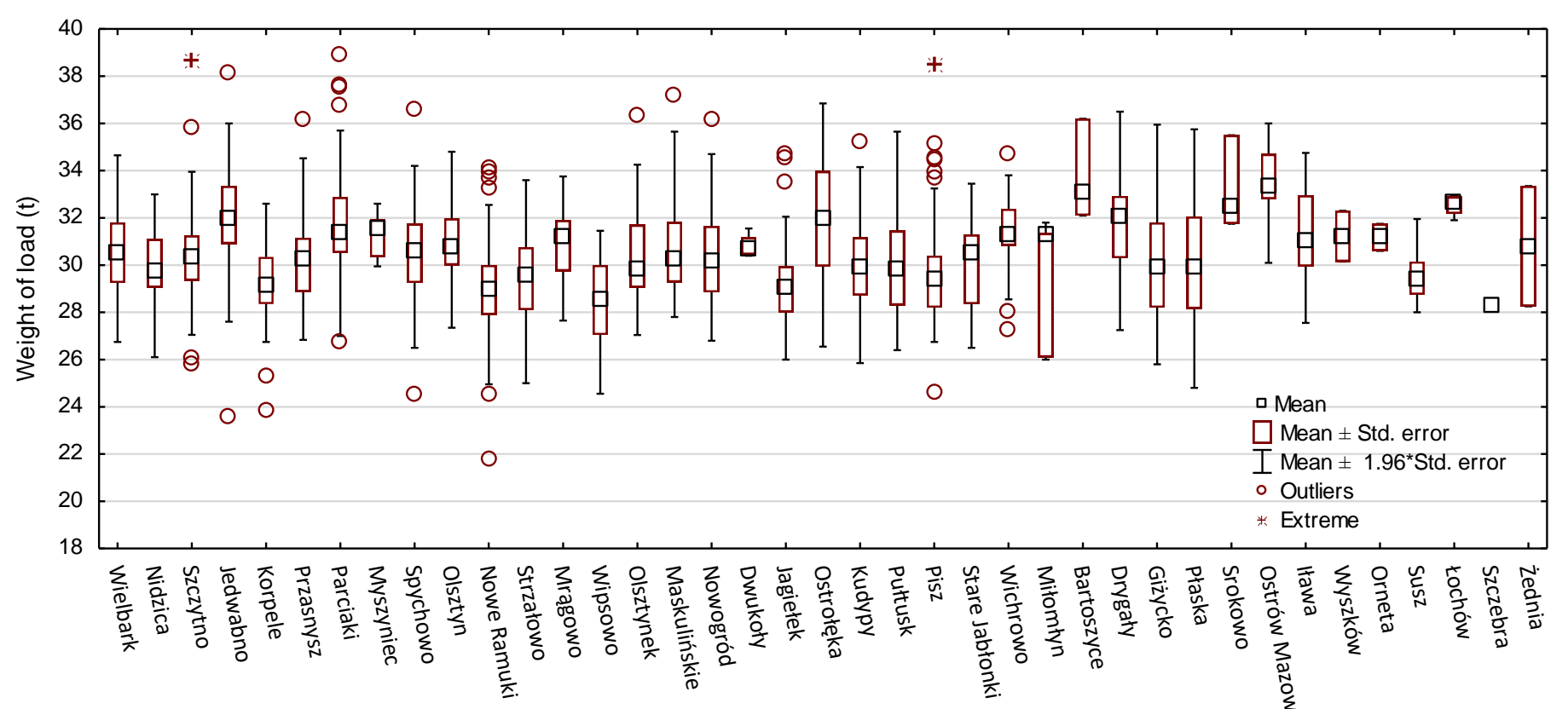

Weight of deliveries from individual forest districts (forest districts in the order of distance from the sawmill). 


\section{Results}

Transport work

The total transport work for the 1,509 journeys analyzed was 3,447,486 tkm.

Average transport performance of one course amounted to 2,286 tkm (SD =1,207).

Minimum value $83 \mathrm{tkm}$, and the maximum as much as $7,803 \mathrm{tkm}$.

The analysis of transport work for a single course according to forest districts showed very large differences. With similar cargo volumes $\left(\mathrm{m}^{3}\right)$ and cargo weight $(\mathrm{kg})$ the transport distance has a significant effect on the transport work.

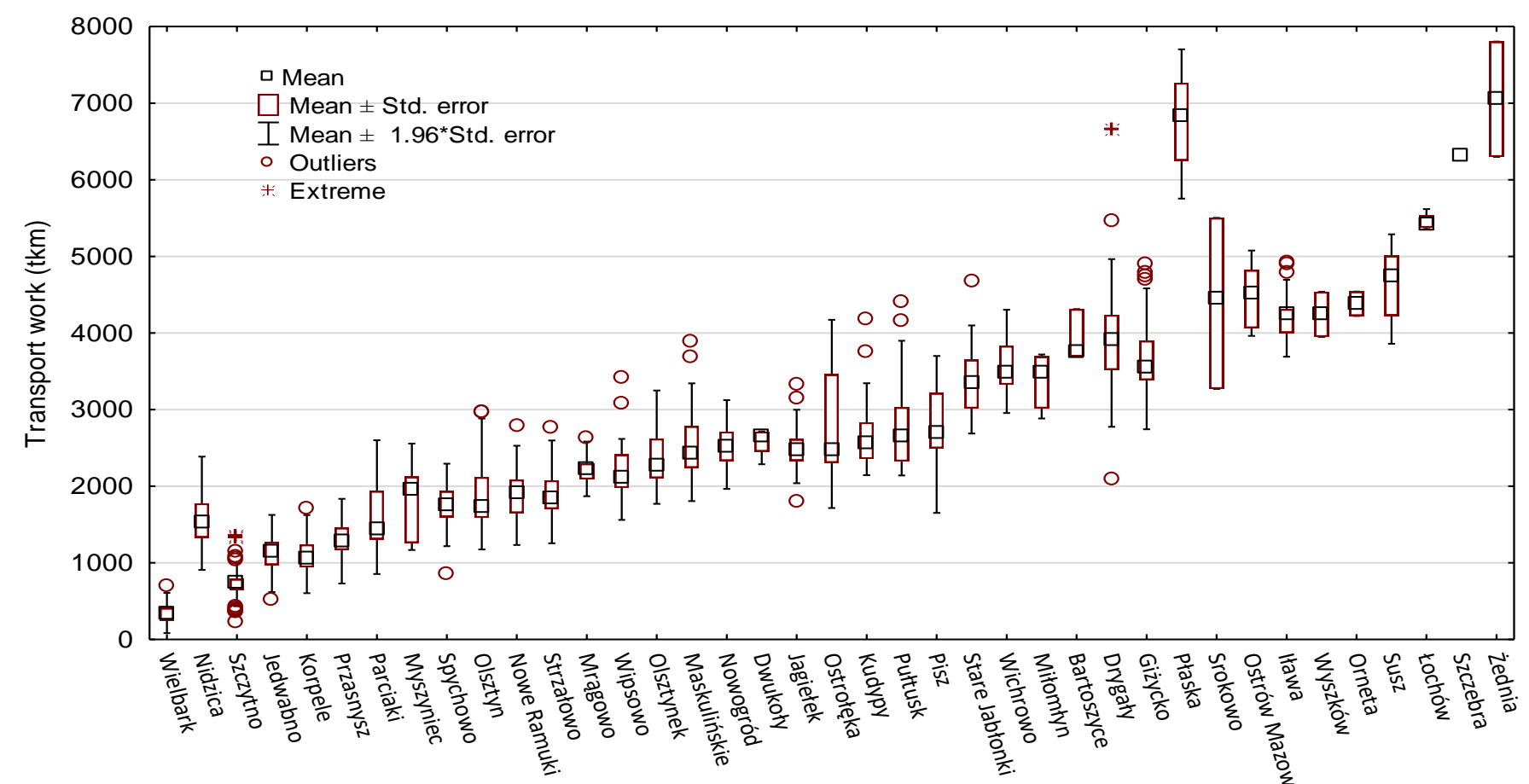




\section{Results}

Transport work

The total transport work performed for the deliveries of wood from individual forest districts depends on the distance from the sawmill and the number of deliveries made. The results show that the supply of raw material in the nearest forest districts requires much less transport work, for example in the Korpele Forest District. Purchase of wood in seven forest districts (Wielbark-Parciaki) up to $50 \mathrm{~km}$ from the sawmill accounts for $30.1 \%$ of the analyzed courses $(1,509)$, resulting in only transport work at the level of $476,104 \mathrm{tkm}$, which is only $13.8 \%$ of the total transport work of all deliveries.

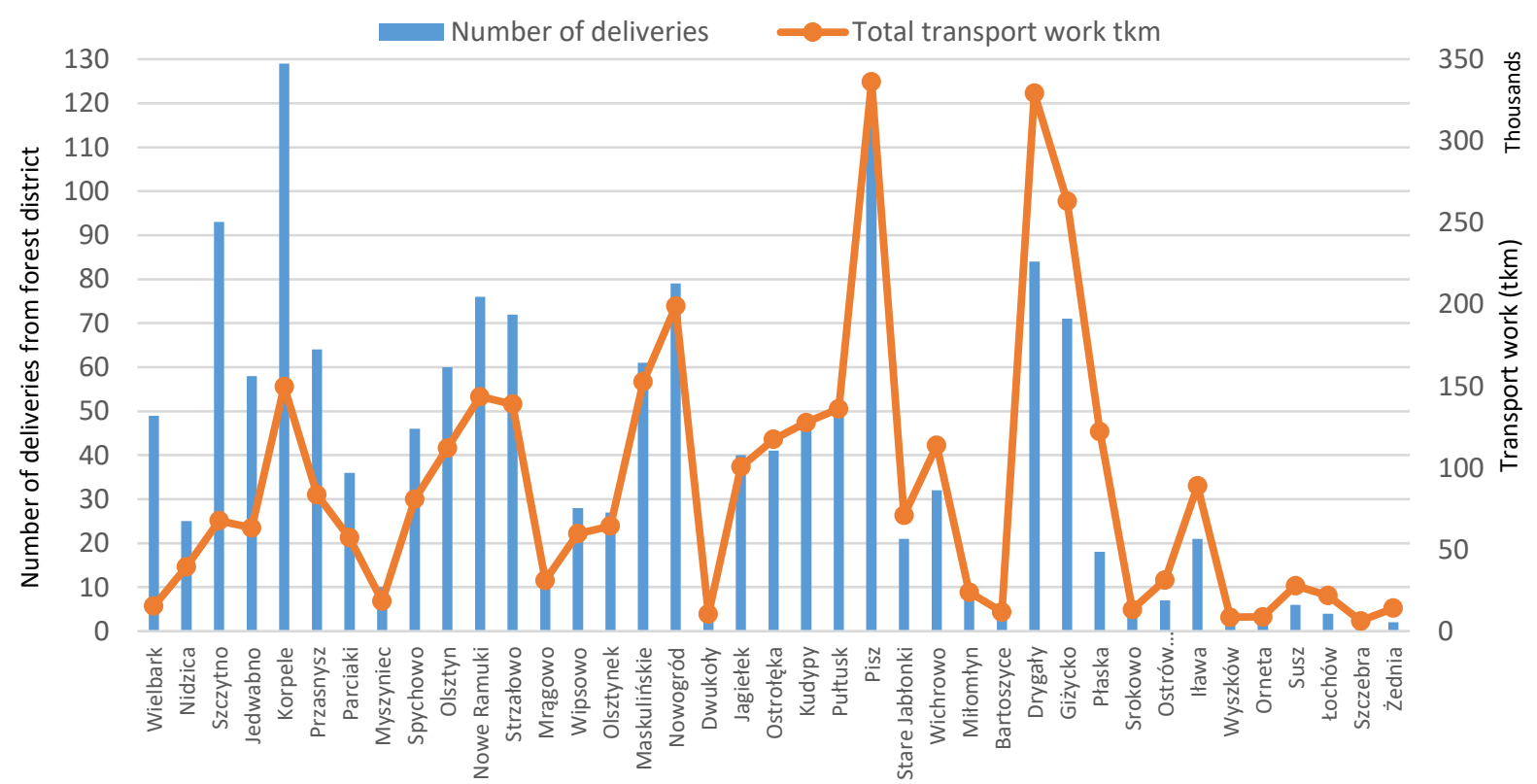




\section{Results}

Optimalization of Transport work

Doubling the number of deliveries made only from the closest 14 Forest Districts, with an average distance from $8.2 \mathrm{~km}$ to $74.0 \mathrm{~km}$ of journeys with a load of timber, it is possible to reduce the generated transport work by $39 \%$ than in the analyzed case.

By increasing the number of deliveries from the nearest forest districts threefold with an average transport distance from 8.2 to $57.1 \mathrm{~km}$, it would be possible to reduce the transport work by $51 \%$ than in the analyzed case.

The calculations were presented for 1,509 transports (14\%) of all completed 9,797 deliveries to the sawmill, so the total reduction in transport work, mainly kilometers traveled, and thus the reduction of $\mathrm{CO} 2$ emissions may be much greater.

Assuming the estimates presented by Rijkswaterstaat [2011], the reduction of the analyzed $113,728 \mathrm{~km}$ of journeys by $39 \%(44,354 \mathrm{~km})$ and $51 \%(58,000 \mathrm{~km})$ in the first and the second analyzed delivery variant, respectively, allows to estimate the reduction of $\mathrm{CO} 2$ emissions at the level of $35.5 \mathrm{t}$ and $46.4 \mathrm{t}$. 


\section{Conclusions}

Most of the deliveries of wood to the sawmill, 180 trips, were related to the journey with cargo over a distance of $70-80$ and $80-90 \mathrm{~km}$.

$30.1 \%$ of deliveries to the sawmill (454 courses) were made from distances of up to 50 $\mathrm{km}$ (average transport distance).

With very similar loads of wood, the travel distances have a significant impact on transport work and to a large extent does not depend on the delivery date, and the number of short-distance trips does not automatically increase it.

It is possible to optimized (reduce) the round wood deliveries, and thus transport work, as a result of a change in the structure of sawlogs sourcing by the sawmill. However, is limited by the regulations and method of selling round wood. 


\section{Thank you for your attention}

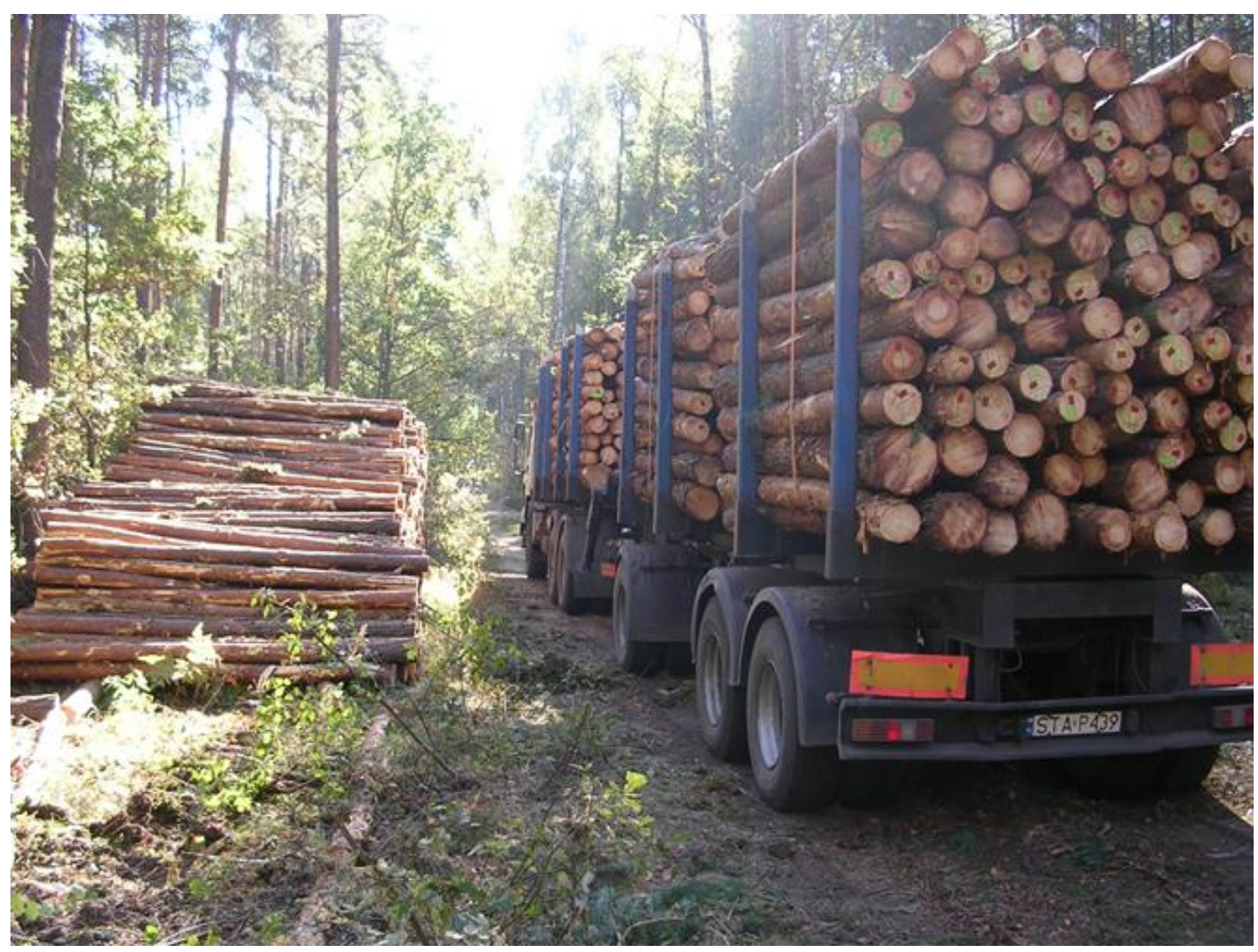

Warsaw University of Life Sciences - SGGW, Institute of Forest Sciences, Department of Forest Utilization 159 Nowoursynowska St., 02-776 Warsaw, Poland 